\title{
Planejamento de ensino na educação infantil: percepções de professores de Educação Física escolar
}

\section{RESUMO}

Este estudo discute como professores de Educação Física escolar compreendem e elaboram o planejamento de ensino na Educação Infantil. Trata-se de uma pesquisa qualitativa realizada com cinco professores de Educação Física, diplomados pela mesma instituição de ensino superior, que atuam na Educação Infantil da rede pública de um município da Região do Vale do Taquari/RS. As informações foram coletadas por meio de entrevistas semiestruturadas, cuja análise de conteúdo originou dois pontos de discussão: (i) planejamento de ensino: das dúvidas à desvalorização do plano de trabalho e (ii) planos de aulas: da busca por atividades às críticas sobre $o$ Ensino Superior. Em conclusão, os professores percebem o planejamento de ensino como documento de fins burocráticos, cuja elaboração é marcada pela escolha de objetivos e seleção de atividades práticas e brincadeiras prontas. Nesse caso, desconsiderando o caráter político e utópico do planejamento e reduzindo o curso de graduação a uma formação técnico-instrumental.

PALAVRAS-CHAVE: Educação física escolar; Planejamento de ensino; Educação infantil; Pesquisa qualitativa
Joana Diedrich

Licenciada em Educação Física Universidade do Vale do Taquari UNIVATES, Departamento de Educação Física, Lajeado, Rio Grande do Sul, Brasil joana.diedrich@yahoo.com.br ${ }^{\oplus}$ https://orcid.org/0000-0002-2552-8157

Samuel Nascimento de Araújo Mestre em Ciências do Movimento Humano Universidade Federal do Rio Grande do Sul UFRGS, Escola de Educação Física, Fisioterapia e Dança, Porto Alegre, Rio Grande do Sul, Brasil araujoedf@hotmail.com

๑https://orcid.org/0000-0003-3601-0617

\section{Leandro Oliveira Rocha}

Doutor em Ciências do Movimento Humano Universidade Federal do Rio Grande do Sul UFRGS, Escola de Educação Física, Fisioterapia e Dança, Porto Alegre, Rio Grande do Sul, Brasil Universidade do Vale do Taquari UNIVATES, leandro.o.rocha@hotmail.com @https://orcid.org/0000-0001-8404-1261 


\begin{abstract}
This study discusses how school Physical Education teachers understand and elaborate teaching planning in the Childhood Education. It is a qualitative research carried out with five Physical Education teachers, graduated from the same higher education institution, who work in Public Elementary School in a municipality in the Region of Vale do Taquari/RS. The information was collected through semi-structured interviews, whose content analysis led to two points of discussion: (i) teaching planning: from doubts to the devaluation of the work plan and (ii) lesson plans: from the search for activities to criticisms about Higher Education. In conclusion, teachers perceive teaching planning as a document with bureaucratic purposes, whose elaboration is marked by the choice of objectives and the selection of practical activities. In this case, disregarding the political and utopian nature of planning and reducing the undergraduate course to technical and instrumental training.
\end{abstract}

KEYWORDS: School physical education; Teaching planning; Childhood education; Qualitative research

\author{
Planificación docente en educación infantil: percepciones de maestros de Educación Física \\ escolar
}

\title{
RESUMEN
}

Este estudio discute cómo los maestros de Educación Física entienden y elaboran la planificación de la enseñanza en la Educación Infantil. Esta es una investigación cualitativa realizada con cinco maestros de educación física, graduados de la misma institución de educación superior, que trabajan en la escuela primaria pública en un municipio de la región Vale do Taquari/RS. Las informaciónes se recopiló a través de entrevistas semiestructuradas, cuyo análisis de contenido condujo a dos puntos de discusión: (i) planificación de la enseñanza y (ii) planes de lecciones. En conclusión, los maestros ven la planificación de la enseñanza como un documento con fines burocráticos, cuya elaboración és marcada por la elección de objectivos y la selección de actividades prácticas; sin tener en cuenta la naturaleza política y utópica de la planificación y la reducción del curso de pregrado para la formación técnica e instrumental.

PALABRAS-CLAVE: Educación física escolar; Planificación de la enseñanza; Educación Infantil; Investigación cualitativa 


\section{INTRODUÇÃO}

$\mathrm{Na}$ busca pela compreensão sobre o planejamento de ensino da Educação Física na Educação Infantil, tema desta investigação, inicialmente nos dedicamos a leituras que tratam o planejamento no contexto educacional. Nesse movimento, compreendemos que o planejamento de ensino integra processos dialógicos sustentado na ação-reflexão-ação, ou seja, mediados por análises reflexivas ao longo do próprio processo educativo (GANDIN, 2002).

Segundo Gandin (2002, p. 18), planejar é uma tarefa vital, "união entre vida e técnica para o bem-estar do homem e da sociedade", cuja finalidade "só é alcançada quando o processo de planejamento é concebido como uma prática que sublinhe a participação, a democracia, a libertação"; no qual o inacabamento humano dá sentido a projetos utópicos de sociedade e à própria existência do planejamento (FREIRE, 2011). Uma vez que planejar localiza um processo passível de ser alterado segundo os contextos sociais e os propósitos educativos, o planejamento é vivo, dinâmico e não pode ser caracterizado como mero instrumento burocrático (AYOUB, 2005). É por isso que o planejamento de ensino leva em consideração a realidade escolar e a reflexão sobre ela, as intenções pedagógicas e as propostas políticas de escolas e redes de ensino (GANDIN, 2002). Sobre a elaboração do planejamento, cabe citar:

O planejamento pedagógico caracteriza-se um guia de orientação e como uma projeção daquilo que desejamos alcançar (projetar possibilidades); é a organização do conhecimento e das ações no tempo; exige o estabelecimento de prioridades; precisa ser flexível - ter abertura para a redefinição das ações, levando em conta os interesses e experiências das alunas e alunos; deve ser elaborado considerando o que vai ser ensinado, para quem vai ser ensinado, porque e para que vai ser ensinado e como vai ser ensinado; precisa ser pensado na articulação entre os seus elementos constitutivos: os conhecimentos, os objetivos, os procedimentos didático-metodológicos e a avaliação do trabalho desenvolvido em relação aos alunos, à atuação do professor, à instituição e ao próprio planejamento (AYOUB, 2005, p. 146).

Em termos práticos, o planejamento de ensino é geralmente composto pelo plano de trabalho e os planos de aulas. O plano de trabalho - também conhecido como plano de ensino ou plano de curso - constitui a proposta de trabalho do componente curricular para o ano letivo, específica para cada turma. Em geral, trata-se de uma proposta organizada em trimestres e elaborada pelo professor durante o primeiro mês de trabalho com os estudantes, a qual relaciona a proposta educativa institucional, os saberes específicos do componente curricular e a prática docente na escola. Em vista disso, a sua elaboração exige consonância com o PPP e as proposições temáticas anuais da escola ou rede de ensino e a visão de sociedade e de estudante que é almejada (NUNES et al. 2017); 
além de considerar "as reais necessidades e condições dos alunos, a organização e estruturação dos conteúdos, a organização dos procedimentos de ensino, as estrutura física e material da escola e a definição dos procedimentos de avaliação em acordo com os objetivos propostos" (FONSECA; MACHADO, 2015, p. 53). Por sua vez, os planos de aulas estabelecem a proposta de ação do professor para uma determinada aula com uma turma, nos quais o professor especifica os procedimentos didáticos diários a serem desenvolvidos conjuntamente com os estudantes para a concretização do plano de trabalho. Desta forma, os planos de aula são detalhadamente descritos: o tema, objetivos específicos e conteúdos de ensino da aula; a sua estruturação dos tempos, comumente organizado em três momentos, início, meio e fim; e as sequências de atividades e os procedimentos metodológicos; sempre considerando a intencionalidade pedagógica e a linha de trabalho definida pelo professor (FONSECA; MACHADO, 2015).

No que se refere à Educação Infantil, o planejamento da Educação Física possui uma visão interdisciplinar, expressa na consolidação de uma pedagogia que potencializa na criança a capacidade de estabelecer suas leituras de mundo, e específica, sustentada nas experiências corporais como forma comunicativa de linguagem (SIMÃO, 2005).

De um lado, a participação interdisciplinar demarca o envolvimento institucional dos professores, que não se limita às aulas de Educação Física, haja vista que seu trabalho pedagógico é compreendido "como parte dos momentos que compõem o cotidiano das unidades, tais como: higiene, alimentação, sono, parque, comemorações, festas da família, mostra educativa, projetos coletivos, reuniões pedagógicas, grupos de estudos, reuniões com as famílias" (FLORIANÓPOLIS, 2016, p. 15). Isso significa que a relação entre educação e corporeidade permeia todos os saberes e períodos que configuram o dia-a-dia das crianças nas instituições de ensino. Assim, sendo necessário que o professor de Educação Física garanta seu espaço nas reuniões pedagógicas, sua inserção no PPP da unidade e, juntamente com seus colegas, defina os princípios pedagógicos que orientam a sua articulação com os outros profissionais e, ao mesmo tempo, o seu trabalho específico, com as práticas corporais mais diretamente ligadas à tradição do seu componente curricular (FLORIANÓPOLIS, 2016).

Por isso, de outro lado, a centralidade do corpo e do movimento na prática pedagógica na Educação Física não pode ser negligenciada. Pelo contrário, devem encontrar espaço privilegiado nessa dinâmica de trabalho porque as crianças se comunicam, expressam-se e interagem socialmente sobretudo pela via corporal, cujos "sentidos/significados" do movimento humano tornam-se fundamentais na mediação didático-pedagógica da Educação Física na Educação Infantil (FLORIANÓPOLIS, 2016, p. 11-12). 
É importante salientar que as expressões e movimentos das crianças são formas de linguagem que expressam o patrimônio cultural da humanidade, cujos "fenômenos da cultura que se expressam a nível corporal, bem como a ampliação, a vivência e a criação das culturas infantis de movimento, constituem a especificidade da contribuição da Educação Física na Educação Infantil" (SIMÃO, 2005, p. 165). Isso significa que as crianças, inclusive as de pouca idade, possuem uma cultura infantil peculiar à sua faixa etária, expressa "pelo brincar, pelo faz-de-conta, pelos jogos, pela imitação e por sua inconfundível capacidade de criar ritmos e movimentos", o que lhes confere "o estatuto de sujeitos histórico-culturais que, em relação com outras crianças e com os adultos, criam e recriam suas linguagens de movimento e, consequentemente, a cultura" (SAYÃO, 1999, p. 233). Como sujeito histórico, a criança representa singularmente as diversas manifestações culturais que apreende em suas atividades cotidianas em família, na escola, nas relações com o mundo. Logo, torna-se fundamental que o planejamento da Educação Física privilegie as diferentes linguagens manifestas através da corporeidade, gestualidade, oralidade, dramaticidade, musicalidade, leitura, escrita. Linguagens essas que são "vividas e percebidas pelo brincar, representam a totalidade do 'ser criança' e precisariam estar garantidas na organização curricular”, ou seja, no currículo da Educação Infantil, não apenas alocadas em áreas do conhecimento (SAYÃO, 1999, p. 234).

Naturalmente, ler a produção intelectual foi decisivo para compreendermos as finalidades do planejamento e suas interfaces com as especificidades da Educação Infantil. Contudo, são as experiências docentes compartilhadas no cotidiano de trabalho na escola que nos incitam a pensar, repensar e questionar o planejamento de ensino da Educação Física na Educação Infantil, obrigando-nos a avançar para novos estudos. Com isso, queremos dizer que o estudo acadêmico aliado ao trabalho docente na Educação Física escolar tem nos mostrado que o planejamento exige problematização (FREIRE, 1996), reflexão na ação (SCHÖN, 2000), propósitos político-educativos, fundamentação teórica, intencionalidade pedagógica definida e objetivos, procedimentos didáticos e avaliativos coesos com as particularidades de cada etapa de ensino e o contexto das comunidades escolares.

Sendo assim, a partir destas informações introdutórias sobre a relevância do planejamento de ensino, do pensamento utópico que permeia os projetos educativos e das experiências docentes, apresentamos as informações da pesquisa acadêmica que desenvolvemos com a proposta de compreender: Como os professores de Educação Física escolar compreendem e elaboram o planejamento de ensino da Educação Infantil? - pergunta que orienta a discussão deste texto e, ao final, nos permite advertir quanto à presença de uma visão técnica instrumental sobre o Ensino Superior. 


\section{PROCEDIMENTOS METODOLÓGICOS}

Com o intuito de contemplar o problema de pesquisa elaborado, realizamos uma pesquisa qualitativa com os cinco professores de Educação Física da rede municipal de ensino de um município localizado na região do Vale do Taquari, estado do Rio Grande do Sul, que foram diplomados pela mesma Instituição de Ensino Superior, aqui denominada Unimodelo. Logo, as "pessoas que participam da pesquisa são reconhecidas como sujeitos que elaboram conhecimentos e produzem práticas adequadas para intervir nos problemas que identificam”, isto é, têm conhecimentos consolidados que dão subsídios para estabelecer suas reflexões (CHIZZOTTI, 2000, p. 83). É importante salientar que a opção por delimitar os participantes da pesquisa segundo a Instituição de Ensino Superior de origem corresponde à possibilidade de relacionar suas respostas com as disciplinas que integram o curso de Educação Física, visto que também estudamos nesta instituição e, por isso, temos acesso aos planos de ensino da matriz curricular do curso, caso necessário para analisar as informações coletadas.

Compondo a primeira etapa da investigação, obtivemos a autorização do coordenador da Secretaria Municipal de Educação (SME) para realizar a pesquisa, por meio da assinatura na Carta de Anuência Institucional, e uma lista de endereços e contatos de todas as Escolas Municipais de Educação Infantil (EMEI) e Escolas Municipais de Ensino Fundamental (EMEF). Em posse dessa lista, contatamos pessoalmente a direção de cada EMEI e EMEF para explicar a pesquisa e identificamos o total de cinco professores de Educação Física diplomados que atuam na Educação Infantil e são diplomados pela Unimodelo. São eles: o professor João, diplomado no ano de 2006; a professora Francieli, diplomada em 2013; as professoras Andressa e Bruna, ambas diplomadas em 2014 e o professor Roberto, diplomado em 2015. Desde já salientamos que todos os nomes próprios utilizados para nos referirmos aos professores e às instituições de ensino são fictícios.

$\mathrm{Na}$ sequência, confirmamos a participação dos cinco professores por meio da assinatura no Termo de Consentimento Livre e Esclarecido (TCLE), tivemos acesso aos seus planos de trabalho e planos de aulas, ao PPP das escolas e coletamos as informações por meio de uma entrevista semiestruturada (TRIVIÑOS, 1987). Nesse caso, a entrevista foi previamente agendada, realizada individualmente com cada professor na escola onde trabalha, gravada em áudio, transcrita e validada, ou seja, a transcrição da entrevista foi lida pelo professor entrevistado e autorizada para ser utilizada na pesquisa.

As transcrições das entrevistas foram analisadas através do procedimento denominado análise de conteúdo, pelo qual é possível entender o sentido da comunicação para, em seguida, 
buscar outra significação. Oscilando entre o rigor da objetividade e a fecundidade da subjetividade, a análise de conteúdo integra o processo de descrever e interpretar para "atingir uma compreensão mais elaborada dos fenômenos e dos discursos no interior dos quais foram produzidos" (MORAES, 2007, p. 89). Desse modo, constituindo uma análise do conteúdo da fala, pois, "contrariamente à linguística, que apenas se ocupa das formas e da sua distribuição, a análise de conteúdo leva em consideração as significações (conteúdo), eventualmente a sua forma e a distribuição desses conteúdos (índices formais e análises de ocorrência)" (BARDIN, 2011, p. 48).

Sendo assim, decorrente do processo analítico, a seguir dialogaremos sobre dois aspectos principais: (i) Planejamento de ensino: das dúvidas à desvalorização do plano de trabalho e (ii) Planos de aulas: da busca por atividades às críticas sobre o Ensino Superior.

\section{Planejamento de ensino: das dúvidas à desvalorização do plano de trabalho}

$\mathrm{Na}$ escola, o plano de trabalho para o ano letivo é elaborado pelo professor de cada componente curricular durante o primeiro mês de trabalho com os estudantes. É organizado em trimestres e constitui a proposta pedagógica dos professores de Educação Física entrevistados para as turmas de Educação Infantil, o que indica a aproximação entre a prática docente, a proposta educativa institucional, os saberes específicos do componente curricular e, por isso, exige aporte teórico e documentos institucionais para embasar as propostas educativas.

A professora Bruna destaca a necessidade de planejar em acordo com a Base Nacional Curricular Comum (BNCC), cuja etapa da Educação Infantil é composta por tabelas com objetivos de aprendizagens divididos por faixa etária e organizados em cinco campos de experiências, são eles: "o eu, o outro e o nós"; "corpo, gestos e movimentos"; "traços, sons, cores e formas"; "escuta, fala, pensamento e imaginação"; "espaços, tempos, quantidades, relações e transformações" (BRASIL, 2018, p. 38-40).

Embora não haja um campo de experiências específico para cada área de conhecimento, a professora Bruna enfatiza que a rede de ensino considera o campo de experiência corpo, gesto e movimento como responsabilidade da Educação Física, como assim explica:

Conforme as orientações da escola, o objetivo principal é aprimorar e desenvolver as habilidades motoras das crianças, e isso é meio engessado. Então, no documento estão identificados vários 'campos de experiência', e o da Educação Física é o campo chamado de 'corpo, gesto e movimento', onde tem os objetivos que devem ser utilizados para usar com os bebês, o berçário, as crianças bem pequenas, os maternais, e crianças pequenas. No documento estão todos os objetivos e eu não posso criar os meus objetivos. Eu tenho de seguir o que está descrito na proposta da escola para a Educação Física (PROFESSORA BRUNA). 
Embora destaque a importância dos documentos oficiais, a professora Bruna queixa-se da falta de autonomia para alterar os objetivos propostos na $\mathrm{BNCC}$, pois entende que não tem liberdade de criar a sua própria proposta de ensino.

Trata-se de um sentimento opostamente apresentado pelo professor Roberto, que localiza o PPP da escola e a BNCC como orientações, visto que os professores tem liberdade para elaborar seu planejamento como achar conveniente. Pensando assim, esse professor afirma que "o principal objetivo de sua proposta é aprimorar o desenvolvimento das crianças, é trabalhar o integral deles, tanto afetiva, ajudando o colega, quanto a parte motora, e o trabalho cognitivo" (PROFESSOR ROBERTO). Diante dessa resposta sucinta, procuramos saber como professor Roberto relaciona o PPP da escola ao seu planejamento, cuja resposta, ainda mais sintética, evidencia a falta de relação com o PPP da escola, visto que, para ele, não apresenta informações específicas para a Educação Física.

Próximo ao que pensa o professor Roberto, a professora Andressa entende que a BNCC e o PPP da escola servem apenas para orientar a elaboração da proposta pedagógica anual, pois não há necessidade de seguir rigorosamente quaisquer documentos fornecidos pela rede de ensino ou pela escola. Segundo essa professora:

Quando tu inicias o ano na escola tem de ter o teu planejamento anual pronto, escrito. Daí, conforme os objetivos, o professor faz as atividades. Eu faço sozinha. [...] Não, nunca me falaram nada sobre a necessidade de relacionar o meu planejamento com o PPP da escola. Eu acho que é porque esta é uma escola de Educação Infantil e não envolve tanto isso. Aqui, tenho mais é que atuar na parte das valências físicas, que é a coordenação motora, o equilíbrio, a agilidade. Por isso o planejamento é focado mais nessa parte (PROFESSORA ANDRESSA).

Esses três professores planejam de modo individualizado e enfatizam que não sabem se há na escola uma proposta coletivamente elaborada para a Educação Infantil, na qual pudessem fazer parte. O mesmo acontece com a professora Francieli, que relata a importância do desenvolvimento motor da criança e planeja de modo individualizado. Porém comenta sobre uma relação de conteúdos de ensino disponibilizados pela escola, a qual não vem sendo alterada e cabe a ela utilizála ou não, conforme comenta:

Para fazer o planejamento, eu começo a pensar no que a gente precisa conseguir fazer em cada fase. Por exemplo, na Educação Infantil, que começa desde o berçário, é preciso saber sentar e desenvolver as qualidades físicas básicas. [...] Não há relação com o PPP, tanto que o PPP eu vi a dois ou três anos atrás, quando entrei aqui na escola. Como eu te comentei, era bem básico, era só proporcionar atividades físicas, ludicidade essas coisas, bem básico mesmo. Então, o que eu sigo é só aquela relação de conteúdos que eles têm aqui na escola (PROFESSORA FRANCIELI). 
Completando as informações coletadas sobre a elaboração do planejamento, o professor João adverte sobre a falta de uma proposta escolar específica para a Educação Física na Educação Infantil, algo que coloca em dúvida o que é esperado com o seu trabalho junto às crianças. Segundo ele:

Nas reuniões pedagógicas a direção coloca o que os alunos devem aprender. Só que, muitas vezes, se torna um pouco confuso porque na Educação Infantil eles pedem para deixar a criança aprender com o lúdico, com recreação e não forçar. Dizem que as crianças vão ter o tempo delas e que precisam brincar, o que na verdade nem sempre dá certo. [...] Se tu for analisar, o documento da escola não é um PPP específico para Educação Infantil, é adaptado. Sabe, hoje, eu acho, surge essa necessidade de mais documentos. Já que falam tanto em educação e importância da educação, seria necessário criar um projeto específico para Educação Infantil (PROFESSOR JOÃO).

Se por um lado as considerações desses professores indicam a falta de uma proposta escolar específica da Educação Física na Educação Infantil, de outro parece haver um pensamento fragmentado em componentes curriculares que prejudica o envolvimento coletivo mais efetivo. Conforme percebemos, os professores planejam de modo individualizado, sem diálogo com o campo da Educação Infantil e com a escola, porque são os únicos professores de Educação Física de suas escolas que atuam nesta etapa da formação da criança. Obviamente isso não os impede de desenvolver propostas interdisciplinares, tampouco de planejar em acordo com o PPP das escolas os quais, conforme analisamos, destacam a formação de pessoas conscientes, éticas, atuantes na vida pública, autônomas, com valores afetivos, princípios de igualdade e respeito à diversidade cultural; enfatizando a importância dos jogos recreativos, das brincadeiras lúdicas e das atividades esportivas e rítmicas no processo educativo.

Assim, a impressão que fica é que os cinco professores entrevistados, em comum, entendem o planejamento como documento institucional necessário para formalizar uma proposta pedagógica junto à rede de ensino e à comunidade escolar e comprovar o que foi realizado, sem considera-lo como ação reflexiva que pressupõe a participação dos sujeitos envolvidos no processo educativo. Ao que parece, os professores desconsideram a própria participação na elaboração e reelaboração das propostas educativas da Educação Infantil e dos projetos de escola, motivo que talvez os leve a entender o planejamento como tarefa burocrática e o PPP como documento burocrático, sem sentido porque não participaram da sua construção ou reconstrução.

Lamentavelmente a ênfase reducionista atribuída ao planejamento de ensino parece condizer com uma perspectiva equivocadamente reproduzida no contexto educacional brasileiro a partir da década de 1960, período no qual o planejamento era conduzido por pessoas e grupos que 
desconsideravam a diversidade dos contextos escolares e as suas finalidades educativas, mantendo um caráter formalista e tecnocrático de obter resultados esperados (KUENZER, 2003). Assim, o planejamento foi se consolidando no âmbito educativo sob a dicotomia teoria e prática, na qual os grupos de teóricos assumiam a autoridade sobre o que deveria ser ensinado, enquanto que, nas escolas, os professores eram responsáveis pela tarefa de ensinar, como meros operários. Em decorrência dessa relação fragmentada:

[...] o planejamento rapidamente perdeu seu significado entre os educadores, deixando de ser entendido como atitude, isto é, um modo de ser, que implica conhecimentos e reflexão sobre a realidade em que se pretende atuar, seleção de meios para intervenção tendo em vista a mudança pretendida, reflexão sobre os resultados obtidos e nova proposição de metas. Em síntese, um processo dialético: ação-reflexão-ação (BALZAN,1996, p. 157).

Mobilizado pela dicotomia teoria e prática, especificamente na Educação Física escolar o planejamento passou a ser compreendido como agrupamento de metas ou aporte metodológicooperacional, uma tarefa de aplicar teorias oriundas da área da administração na escola que o transformava em um documento determinista e controlador, inclusive para ação pedagógica planejada (BOSSLE, 2003).

Devido à concepção equivocada de planejamento, muitas vezes as teorias de ensino da Educação Física escolar foram entendidas como respostas práticas às dúvidas sobre como fazer, como ensinar ou como treinar. Consequentemente, dúvidas como essas fomentaram a preponderância de manuais compostos por formas de exercitação, as indicações de procedimentos de ensino e a "pouca ou nenhuma preocupação com a discussão em torno das finalidades sociopolíticas da Educação Física” (CAPARRÓZ; BRACHT, 2007, p. 24).

Daí que, em contraponto a essa visão reducionista, autores como Aguiar e Marçal (2010) enfatizam que o planejamento da Educação Física deve conter conteúdos de ensino definidos e flexibilidade para que seja possível instigar e incentivar a reflexão e a construção coletiva de conhecimento a partir das diversas situações do dia a dia associadas à discussão da cultura corporal. Assim, o planejamento da Educação Física escolar contemplaria a função docente de "promover o ensino-aprendizagem de maneira completa, complexa e lúdica, além de ser capaz de colocar em evidência as diferenças culturais, corporais e sociais da população envolvida" (AGUIAR; MARÇAL, 2010, p. 8). Sendo que nesse sentido, as práticas pedagógicas da Educação Física assumiriam "o propósito de avançar para além do movimento pelo movimento", exigindo entender o planejamento como ação contrária ao ensino pelo improviso e sem intencionalidade pedagógica definida (FONSECA; MACHADO, 2015, p. 34). 
O problema é que reclamar da falta de documentos institucionais específicos da Educação Física - como é o caso dos professores entrevistados - localiza certa desconsideração da importância de discutir e construir um projeto educativo coletivamente com professores de outras áreas de conhecimento; o que se torna vital para pensar uma proposta de ensino que garanta, ao mesmo tempo, os saberes da Educação Física e as particularidades da Educação Infantil: não conteudista, não escolarizada em tempos fragmentados por aulas. Com isso, queremos salientar que a percepção de que falta apoio escolar está intimamente relacionada às dúvidas destes professores sobre a Educação Física na Educação Infantil.

Tal como informado, os professores entrevistados têm muitas dúvidas quanto ao trato pedagógico na Educação Infantil e sentem necessidade de modelos de propostas de ensino escritas, contendo possibilidades teórico-metodológicas, autores de referência e, inclusive, exemplos ou indicação de práticas pedagógicas e atividades para ser desenvolvidas com os bebês e as crianças. Com efeito, o ato de planejar parece restrito à identificação e escolha de atividades que nem sempre estão amparadas em um projeto maior. Em vez de assumir a política educativa da escolar e, depois, elaborar práticas de ensino alicerçadas no campo de conhecimento da Educação Física, estes professores elaboram planos de ensino de cunho generalizado, no qual identificam saberes da área e atividades práticas que pretendem realizar com as crianças, sem a preocupação de contemplar a proposta educativa de escola porque não a reconhecem.

Não obstante, o interesse por propostas prontas e específicas para a Educação Física na Educação Infantil somado ao individualismo revela a autonomia na elaboração do planejamento, o que não seria problemático se parecesse limitada à elaboração dos processos didático-pedagógicos. Conforme enfatizam Caparróz e Bracht (2007), é importante que os professores reconheçam sua autoridade na construção de propostas condizentes com a realidade da comunidade escolar e as finalidades escolares. Segundo os autores:

A docência exige inevitavelmente a clareza a respeito da impossibilidade de se separar o ensino dos conteúdos da formação ética dos educandos, tampouco se pode incorrer em outras dicotomias que levem à divisão da autoridade e da liberdade, a ignorância do saber, o respeito ao professor do respeito aos alunos, ensinar de aprender. Reconhecer sua autoridade docente leva o professor a buscar compreender e construir sua autoria docente que se baseia constantemente no processo contínuo de ação-reflexão-ação no cotidiano da prática pedagógica, em que o professor necessita perceber-se como construtor desta e não como seu mero executor (CAPARRÓZ; BRACHT, 2007, p. 31).

Se concordarmos que o professor é autor do seu planejamento de ensino, naturalmente observando a política escolar, o trabalho em colegiado e os saberes específicos da sua área, talvez as reclamações apontadas pelos professores entrevistados indiquem a falta de planejamento coletivo e 
definição clara do plano de ação anual da escola. Nesse caso, indica que a função da escola não é estabelecer a conexão direta entre as especificidades das diferentes áreas de conhecimento e o plano de trabalho, visto que esta é uma das funções dos professores. Logo, à cargo de sua autoridade docente, entendemos que os professores entrevistados têm a possibilidade de assumir autoria no planejamento de ensino, no que se refere à proposta formativa e às atividades que pretende desenvolver cotidianamente no trato pedagógico com os estudantes.

Contudo, a dúvida sobre "o que" ensinar e "como" ensinar são maximizadas pela complexidade do contexto escolar e o entendimento que falta uma proposta de Educação Física específica para a Educação Infantil, culminando em um processo gradativo de desvalorização do plano de trabalho e encobrindo seu caráter formativo e utópico presente no plano de trabalho (GANDIN, 2002). Por conseguinte, o plano de trabalho torna-se menos importante em comparação direta com as preocupações que emergem das práticas pedagógicas frente o que acontece no dia a dia escolar. Tal como identificado por Caparróz e Bracht (2007, p. 22), uma colaboradora de pesquisa, professora de Educação Física dos anos iniciais do ensino fundamental recém diplomada, "estava percebendo que lhe faltava embasamento para saber o que ensinar, como ensinar e para quem ensinar", o que gerava a grande dificuldade para elaborar o planejamento de ensino.

Por isso no contexto que investigamos os professores direcionam seus esforços para as atividades práticas que pretendem desenvolver com as crianças durante a aula, algo que justificaria a atenção atribuída aos planos de aulas e, segundo eles, legitimaria as críticas sobre a formação inicial e a defesa de um curso técnico-instrumental - como veremos a seguir.

\section{Planos de aulas: da busca por atividades às críticas sobre o Ensino Superior}

Conforme apontado na discussão anterior, a maior dificuldade dos professores entrevistados é elaborar as práticas pedagógicas que compõem os planos de aulas, uma vez que, diferente dos planos de trabalho, que servem para formalizar e registrar a proposta pedagógica do ano letivo, são observáveis, passíveis de análise e pressupõe o que pretende-se desenvolver cotidianamente com os estudantes. Pensando assim, a professora Andressa centra sua atenção na proposta das aulas e afirma: "priorizo a coordenação motora, que, então, envolve tudo. Por exemplo, o equilíbrio, a agilidade, a força, a lateralidade".

De modo semelhante, a professora Francieli também destaca a preocupação com o desenvolvimento psicomotor e esclarece o modo como pensa e elabora as aulas: 
O objetivo principal é tentar melhorar a parte motora e a capacidade deles entenderem as brincadeiras". [...] Não, escolher uma metodologia e autores a gente só fazia na época de faculdade mesmo. Depois, tu segues o que tem de conteúdos e procura por atividades novas. Não sigo esse autor ou aquele autor, isso também não é exigido da gente na prática, entende? Também não há exigência de relacionar o objetivo proposto para a aula e o que tu faz, com a atividade que tu usa (PROFESSORA FRANCIELI).

Naturalmente, há grande preocupação em desenvolver práticas pedagógicas condizentes com a faixa etária dos estudantes e as necessidades de desenvolvimento motor. Todavia, não há maiores preocupações em o aporte teórico-metodológico ou autores de referência, visto que todos afirmam que não utilizam uma metodologia de ensino definida porque focam na parte prática da aula, algo que pode ser ilustrado pelas seguintes falas:

Sigo mais a prática. [...] Eu vou mais por livros de práticas, eu busco prática de acordo coma faixa etária. Então, eu foco mais na atividade, no objetivo daquela atividade. Começo a relacionar pra mim, como professor, se é uma atividade que é importante naquela faixa etária e o que ela vai trabalhar e se realmente vou ter uma progressão futuramente com ela. Eu não sou muito ligado à teoria, teoria, teoria. Eu sou mais da prática mesmo, de fazer funcionar (PROFESSOR ROBERTO).

Para planejar as aulas eu uso bastante um autor que é de atividades recreativas, mas não sei se ele é um autor famoso na Educação Física, soube dele no magistério, as professoras trabalharam bastantes atividades. Então, busco esse autor porque conheci através do magistério. [...] Ele trabalha através de brincadeiras cantadas com música envolvendo o corpo. [...] Assim, nas aulas de Educação Infantil, durante o curso de Educação Física, a gente não teve aquela base toda como nas outras. A gente não aprendeu bem. Eu sinto que teve uma carência disso quando a gente estava na graduação e, então, a gente vai buscar onde a gente aprendeu um pouquinho (PROFESSORA BRUNA).

Na dúvida sobre como realizar as aulas, os professores entrevistados recorrem à bagagem de conhecimentos e experiências construídos durante a formação inicial. Contudo, a principal estratégia utilizada para planejar as aulas é buscar por modelos de brincadeiras e atividades prontas em manuais, sites ou vídeos disponibilizados na internet, uma necessidade que eles relacionam com fragilidades na formação inicial, conforme identificado na fala da professora Bruna.

Em relação ao que é planejado, podemos destacar um certo reducionismo ao desenvolvimento motor e psicomotor da criança, algo preocupante se observarmos que a Educação Física comprometida com o respeito aos interesses, necessidades e direitos das crianças na faixa etária de 0 a 6 anos deve permitir que elas "desempenhem um papel mais ativo em seus movimentos, respeitando os seus interesses e necessidades e que, nesta faixa etária, só pode se caracterizar pela brincadeira , ampliando assim as culturas infantis de movimento" (SIMÃO, 2005, p. 168). Sobre esse aspecto, Simão (2005) adverte que as práticas corporais das crianças, sejam 
brincadeiras ou quaisquer outras, não podem ser vistas apenas no seu aspecto funcional de contribuição na construção de aprendizagens motoras ou de rendimento esportivo.

Cada criança tem suas maneiras de pensar, brincar, jogar, expressar-se e construir sua cultura de movimento (BASEI, 2008). Se insistirmos em ver as brincadeiras apenas como função pedagógica, limitamos suas possibilidades formativas e impedimos que a criança crie e recrie formas de brincar e se expressar; até porque "a convivência no dia a dia com as crianças nos faz perceber que elas brincam para satisfazer uma necessidade básica que é viver a brincadeira" (SIMÃO, 2005, p. 168). Afinal, quando se expressa, a criança:

[...] o faz com todo o seu corpo, por intermédio dos gestos, da oralidade... Ela não é um ser corporal agora e cognitivo depois. Na brincadeira, a criança é um ser único que demonstra, por intermédio de seus movimentos, uma totalidade. Fragmentá-la e fragmentar as formas que podem levá-la a construção de novos conhecimentos, a um desrespeito (SAYÃO, 1999, 233-234).

Diante do fato de os planos de aulas serem compostos por exemplos de atividades prontas e da crítica à fragilidade da formação inicial, procuramos saber dos professores entrevistados quais são os componentes curriculares do curso de Educação Física de maior relevância para a sua formação. Nas respostas dos professores, é notável o valor atribuído àqueles com carga teóricoprática, sobretudo aqueles componentes curriculares compostos por atividades práticas e passiveis de serem diretamente vinculadas ao fazer docente na escola. Para exemplificar, a professora Bruna enfatiza que: "a Psicomotricidade a gente viu meio por cima; ainda acredito que a principal disciplina do curso, que eu atuo agora, é a Recreação". O mesmo componente curricular é lembrado pelo professor João, o qual procura justificar a sua resposta: “como atuo na Educação Infantil, entendo que a disciplina mais importante seria a Recreação; [...] é fundamental um ambiente bastante recreativo, bem planejado". Por sua vez, o professore Roberto apresenta mais opções e detalhes: "As disciplinas mais importantes foram as aulas práticas; as aulas de práticas esportivas foram todas importantes, de todos os esportes. Querendo ou não, tenho de saber as regras dos esportes dentro das minhas atividades. A Psicomotricidade e a Recreação também foram importantes".

Embora as professoras e os professores entrevistados entendam que não há como julgar a potencialidade de um componente curricular, todos acreditam que alguns não agregam conhecimentos necessários porque não serão ocupados ao dar aula. Com efeito, acreditam que há saberes que podem ser importantes, mas não sejam úteis no exercício da profissão docente e, sendo assim, parecem desnecessários. Para identificar esses componentes curriculares, cabe citar: 
Olha, Gestão do Esporte, porque ela não tem nada ligado à escola. Essa disciplina discute mais a questão de projetos públicos, esportes e lazer, a questão pública, principalmente do município. Assim, talvez para o bacharel em Educação Física essa disciplina sirva, mas para licenciatura não tem utilidade (PROFESSORA BRUNA).

Estudos Sócio Culturais do Movimento Humano eu não aproveitei. Digo e repito: nenhuma disciplina não serve para nada. Todas servem para alguma coisa, mas algumas delas, para mim, para o meu dia a dia, até agora não utilizei. Tem disciplina que talvez futuramente, em algum dia, posso usar porque vai focar aquilo que era tratado, mas, por enquanto não usei (PROFESSOR ROBERTO).

As disciplinas de História da Educação Física e de Estudos Sócio Culturais do Movimento Humano eu não aproveitei. Talvez porque não gostei, não me identifiquei ou nunca fiz muito aproveitamento dela. Acho que hoje as disciplinas importantes são aquelas que têm a teoria e prática, as duas juntas. Acho que estas desenvolvem melhor o que é tratado do que aquelas que são só teóricas (PROFESSORA ANDRESSA).

Notamos que a análise destes professores condiz com as reflexões de Figueiredo (2004), segundo a qual os acadêmicos, quando analisam os cursos de licenciatura, muitas vezes cometem equívocos quando atentam somente para os conhecimentos diretamente vinculados à prática docente, entendendo que há disciplinas mais importantes para a sua formação porque estão diretamente relacionadas ao campo de atuação, enquanto outras não são.

Segundo Figueiredo (2004, p. 106), isso ocorre porque muitos acadêmicos atribuem uma utilidade prática ao conhecimento, diretamente relacionada aos espaços de trabalho e, assim, “esperam extrair das disciplinas os conteúdos e a forma que atendam aos seus interesses". Trata-se de um equívoco que pode representar um aspecto comum, como alerta Rodrigues (2006):

[...] todos concordam com uma formação crítica e reflexiva, incluindo alunos e professores, entretanto esta questão vem sendo pouco debatida no interior das licenciaturas em Educação Física e muitos licenciandos e professores, na realidade, estão falando em ensino crítico e reflexivo sem realmente incorporar este discurso à sua prática, talvez porque o tema não tem encontrado o espaço necessário para sua real apreensão (RODRIGUES, 2006, p. 53).

De fato, é o que parece ocorrer com os professores entrevistados, uma vez que as disciplinas mais centradas nos conhecimentos teórico-conceituais não têm o mesmo reconhecimento daquelas com caráter mais prático, de relação direta com as práticas pedagógicas. Conforme identificado, os professores entrevistados não percebem ou não valorizam os conhecimentos vinculados à formação reflexiva, geralmente construídos em componentes curriculares com densa carga horária de discussão teórica, geralmente em sala de aula. Da relação entre saberes úteis e inúteis, os professores participantes não entendem o Ensino Superior como processo de formação de professores em sentido amplo e crítico, pois detêm suas análises aos procedimentos que tiveram 
acesso e podem ser aplicáveis. Em outras palavras, esses professores entendem que um conhecimento somente tem valor quando pode ser aplicado ou utilizado de modo prático no cotidiana na escola, e quando não é aplicável, não é útil e, por isso, não tem valor.

A mesma perspectiva pode ser associada ao modo como planejam as aulas e pensam a Educação Física na Educação Infantil, uma vez que, buscam por atividades prontas, aplicáveis e úteis, reduzindo essa etapa da educação ao desenvolvimento motor e mero aprendizado procedimental. Embora analisar o nível do desenvolvimento motor da criança seja pertinente e os professores demonstrem preocupação com práticas pedagógicas que favoreçam a interação social, laços afetivos e princípios cognitivos, as aulas são compreendidas como momentos de recreação, indicando claro reducionismo do campo de conhecimento da Educação Física escolar. Conforme explica Fonseca e Machado (2015):

Na Educação Física, como em qualquer outra disciplina, a estruturação das aulas deve ser organizada em três momentos, início, meio e fim, que apesar de terem características próprias, se relacionam entre si. Portanto, não são estanques, cada momento cumpre uma função importante no todo do processo de ensinoaprendizagem que ocorre ao longo da aula (FONSECA; MACHADO, 2015, p. 65).

A partir destas considerações, entendemos que os professores entrevistados têm desconsiderado que toda prática pedagógica carrega em si uma bagagem teórica historicamente produzida que estrutura uma concepção sobre o ensino, e que as metodologias de ensino, mais do que métodos, são aportes teóricos que permitem organizar e sustentar tanto o planejamento de ensino e as práticas pedagógicas quanto a própria legitimidade da Educação Física. Em certa medida, é compreensível que alguns professores atribuam maior valor aos saberes vinculados diretamente ao desenvolvimento de práticas pedagógicas. Porém, desconsiderar os saberes de cunho filosófico e sociológico e reflexivo pode indicar a falta de clareza sobre a formação intelectual e crítica do professor, algo que também pode ser relacionado às dificuldades de relacionar o planejamento de ensino com o engajamento político e a autoria didático-pedagógica. Tal como advertem Pimenta e Lima (2005/2006, p. 4) “as habilidades não são suficientes para a resolução dos problemas com os quais se defrontam, uma vez que a redução às técnicas não dá conta do conhecimento científico nem da complexidade das situações do exercício desses profissionais”. Por isso é fundamental que o professor assuma o protagonismo na construção do seu conhecimento cientifico, reflexivo e técnico-prático longo dos cursos de graduação, indicando que o Ensino Superior potencializa um processo de formação humana, jamais restrito à mera instrumentalização técnica. 


\section{CONSIDERAÇÕES FINAIS}

Ao retomar a questão orientadora desta pesquisa - Como os professores de Educação Física escolar compreendem e elaboram o planejamento de ensino da Educação Infantil? - identificamos que os cinco professores de Educação Física participantes têm focado sua atenção na busca por atividades práticas para desenvolver com as crianças, desconsiderando o caráter reflexivo a finalidade política e utópica do plano de trabalho, o que indica falta de clareza sobre a função educativa transformadora que permeia o planejamento de ensino nas instituições escolares. Tal como esclarece Pérez Gómez (1998):

A função educativa da escola, portanto, imersa na tensão dialética entre reprodução
e mudança, oferece uma contribuição complicada mas específica: utilizar o
conhecimento, também social e historicamente construído e condicionado, como
ferramenta de análise para compreender, para além das aparências superficiais do
status quo real - assumido como natural pela ideologia dominante - o verdadeiro
sentido das influências de socialização e os mecanismos explícitos ou disfarçados
que se utilizam para sua interiorização pelas novas gerações (PÉREZ GÓMEZ,
1998, p. 22).

Nesse caso, os professores entrevistados entendem que os planos de trabalho cumprem uma função burocrática, por vezes desconectada da realidade escolar, e que tanto o PPP da escola quanto a BNCC são insuficientes para elaborar um planejamento de ensino coeso e específico da Educação Física na Educação Infantil. Além de não perceberem que o planejamento de ensino pressupõe propostas pedagógicas elaboradas coletivamente na escola e a autonomia didático-pedagógica para construí-lo reflexivamente nos contextos escolares, os professores direcionam seus esforços na elaboração dos planos de aulas, entendidos como conjuntos de atividades práticas, voltadas, basicamente, para o desenvolvimento motor e a socialização das crianças.

Não obstante, a falta de experiência docente na Educação Infantil somada à dúvida sobre o que fazer no trato pedagógico com as crianças, leva esses professores a reduzirem o ato de planejar à cópia de objetivos pré-estabelecidos na BNCC e à busca por atividades prontas em livros e sites na internet. Por conseguinte, os professores relativizam a importância de planejar, não percebem o ato pedagógico como um ato político (FREIRE, 1996) e não compreendem que, "do ponto de vista educacional, o planejamento é um ato político-pedagógico porque revela intenções e a intencionalidade, expõe o que se deseja realizar e o que se pretende atingir" (LEAL, 2005, p. 1).

Corroborando com o estudo de Sayão (1999), as considerações desta pesquisa reforçam as problemáticas que envolvem a elaboração de currículos da Educação Física escolar que considerem a singularidade da criança de quatro a seis anos de idade. Torna-se ainda mais preocupante se 
relembrarmos a individualidade dos professores, a falta de aporte teórico próprio para a Educação Infantil e a restrição da intencionalidade pedagógica ao desenvolvimento motor, pois reitera a necessidade de ultrapassar "a visão fragmentária que compartimenta o conhecimento, tanto em disciplinas como em práticas pedagógicas situadas em momentos estanques e sem relação com a 'rotina de trabalho', impedindo a visão de totalidade das ações que envolve o trabalho pedagógico" (SAYÃO, 1999, p. 235, grifo da autora).

Em conclusão, percebemos que a visão sintética sobre o planejamento de ensino também está associada às falhas atribuídas ao curso de graduação em Educação Física, reduzido à mera formação técnico-instrumental. Em vez de compreenderem o Ensino Superior como processo de formação reflexiva e crítica, sustentado na produção intelectual e na política educativa institucional de nível superior, estes professores limitam a formação inicial à aquisição de saberes procedimentais, como um momento de aprender atividades aplicáveis em sala de aula. Por isso, reiteramos a importância da pesquisa na escola, com os professores, para problematizar a Educação Física na Educação Infantil e, por que não, no Ensino Superior.

Afinal, se as considerações desta pesquisa revelam a importância de problematizar o planejamento de ensino diante das dificuldades enfrentadas pelos docentes, torna-se fundamental a reflexão, na formação inicial e continuada, sobre as especificidades da Educação Infantil, a potencialidade da Educação Física na construção das experiências das crianças com a cultura corporal de movimento e planejamentos coletivos, que não reproduzam a fragmentação de tempos, espaços e conteúdos - típicos do ensino fundamental.

\section{REFERÊNCIAS}

AGUIAR, Elton José da Silva; MARÇAL, Izabela Lobato. Planejamento em Educação Física: ocorre de fato? In: Congresso Norte-Brasileiro de Ciências do Esporte, 3, 2010. Anais. Castanhal e Belém:

CONCENO, 1-4, dez., 2010. Disponível em:

http://congressos.cbce.org.br/index.php/3conceno/3conceno/paper/viewFile/4667/2263. Acesso em: 30 abril 2020.

AYOUB, Eliana. Narrando experiências com a educação física na educação infantil. Revista Brasileira de Ciências do Esporte, Campinas, v. 26, n. 3, p. 143-158, maio 2005. Disponível em http://revista.cbce.org.br/index.php/RBCE/article/view/165. Acesso em: 04 set. 2020.

BALZAN, Newton Cesar. O Conceito de Planejamento e sua aplicação aos Sistemas Educacionais e às Atividades de Ensino: alcance e limites no linear do século XXI. Educação Brasileira, v. 18, p. 151-172, 1996.

BASEI, Andréia Paula. A Educação Física na Educação Infantil: a importância do movimentar-se e suas contribuições no desenvolvimento da criança. Revista Iberoamericana de Educación, n. 47/3, 25 out. 
2008. ISSN: 1681-5653. Disponível em https://rieoei.org/historico/deloslectores/2563Basei.pdf. Acesso em: 04 set. 2020.

BARDIN, Laurence. Análise de conteúdo. São Paulo: Edições 70, 2011.

BOSSLE, Fabiano. Planejamento de ensino dos professores de educação física do $2^{\circ}$ e $3^{\circ}$ ciclos da rede municipal de ensino de Porto Alegre: um estudo do tipo etnográfico em quatro escolas desta Rede de Ensino. 2003. 271 f. Dissertação. Mestrado em Ciências do Movimento Humano). UFRGS, Porto Alegre.

BRASIL. Base Nacional Curricular Comum. Brasília, DF: MEC, 2018. Disponível em http://basenacionalcomum.mec.gov.br/images/BNCC_EI_EF_110518_versaofinal_site.pdf. Acesso em: 30 dez. 2020.

CAPARRÓZ, Eduardo C.; BRACHT, Valter. O tempo e o lugar de uma didática da educação física. Revista Brasileira de Ciências do Esporte, Campinas, v. 28, n. 2, p. 21-37, jan. 2007.

CHIZZOTTI, Antonio. Pesquisa em ciências humanas e sociais. 4. ed. São Paulo: Cortez, 2000.

FIGUEIREDO, Zenólia Christina. Campos. Formação docente em Educação Física: experiências sociais e relação com o saber. Movimento, Porto Alegre, v. 10, n. 1, p. 89-111, jan./abril, 2004.

FLORIANÓPOLIS. Prefeitura Municipal de Florianópolis. Secretaria Municipal de Educação. A Educação Física na Educação Infantil da Rede Municipal de Ensino de Florianópolis. Florianópolis, SC, SME, 2016, 116 p. ISBN.: 978-85-69486-03-9. Disponível em:

http://www.pmf.sc.gov.br/arquivos/arquivos/pdf/13_06_2017_9.23.33.5187fb803460dd1cd26a6eb383715fd 8.pdf. Acesso em: 04 set. 2020.

FONSECA, Denise Grosso da; MACHADO, Roseli Belmonte. Educação Física: (re)visitando a didática. Porto Alegre: Sulina, 2015.

FREIRE, Paulo. Pedagogia da autonomia. 35. ed. São Paulo: Paz e Terra, 1996.

GANDIN, Danilo. Planejamento como prática educativa. 12. ed. São Paulo: Loyola, 2002.

KUENZER, Acácia Zeneida. Política educacional e planejamento no Brasil: os descaminhos da transição. In: KUENZER, Acácia Zeneida; CALAZANS, Maria Julieta Costa; GARCIA, Walter. Planejamento e educação no Brasil. 6. ed. São Paulo: Cortez, p. 55-89, 2003.

LEAL, Regina Barros. Planejamento de ensino: peculiaridades significativas. Revista Iberoamericana de Educación, Espanha, n. 37/3, p. 1-7, jan./abril, 2005.

MORAES, Roque. Mergulhos discursivos: análise textual qualitativa entendida como processo integrado de aprender, comunicar e interferir em discursos. In: GALIAZZI, Maria do Carmo; FREITAS, José Vicente. Metodologias emergentes de pesquisa em educação ambiental. Ijuí: Unijuí, p. 85-114, 2007.

NUNES, Luciana de Oliveira; FONSECA, Denise Grosso da; BOSSLE, Cibele Biehl; BOSSLE, Fabiano. Planejamento de ensino e Educação Física: uma revisão de literatura em periódicos nacionais.

Motrivivência, Florianópolis, v. 29, n. 52, p. 280-294, set. 2017. Disponível em: https://periodicos.ufsc.br/index.php/motrivivencia/article/view/2175-8042.2017v29n52p280. Acesso em: 20 mar. 2020.

PÉREZ GÓMEZ, Angel Ignacio. As funções sociais da escola: da reprodução à reconstrução crítica do conhecimento e da experiência. In: SACRISTÁN, José Gimeno; PÉREZ GÓMEZ, Angel Ignacio.

Compreender e transformar o ensino. 4 ed. Porto Alegre: Artmed, p. 13-26, 1998. 
PIMENTA, Selma Garrido; LIMA, Maria Socorro Lucena. Estágio e docência: diferentes concepções. Revista Poíesis, v. 3, n. 3/4, p. 5-24, 2005/2006.

RODRIGUES, Anegleyce Teodoro. A questão da formação de professores de educação física e a concepção de professor enquanto intelectual - reflexivo - transformador. Pensar a Prática, v. 1, p. 48-58, nov. 2006.

SAYÃO, Deborah Thomé. Educação Física na Educação infantil: Riscos conflitos e controvérsias.

Motrivivência, Florianópolis, n. 13, p. 221-236, jan. 1999. ISSN 2175-8042. Disponível em:

https://periodicos.ufsc.br/index.php/motrivivencia/article/view/14408/13211. Acesso em: 04 set. 2020.

SCHÖN, Donald. Educando o profissional reflexivo. Porto Alegre: Artmed, 2000.

SIMÃO, Márcia Buss. Educação Física na Educação Infantil: refletindo sobre a "hora da Educação Física". Motrivivência, Florianópolis, a. 17, n. 25, p. 163-173, dez. 2005. Disponível em:

https://periodicos.ufsc.br/index.php/motrivivencia/article/view/4701/3879. Acesso em: 04 set. 2020.

TRIVIÑOS, Augusto Nibaldo Silva. Introdução à pesquisa em ciências sociais: a pesquisa qualitativa em educação. São Paulo: Atlas, 1987.

\section{NOTAS DE AUTOR}

AGRADECIMENTOS - Não se aplica.

\section{CONTRIBUIÇÃO DE AUTORIA}

Concepção do manuscrito: L. O. Rocha, J. Diedrich, S. N. Araújo

Coleta de dados: J. Diedrich.

Análise de dados: J. Diedrich, L. O. Rocha

Discussão dos resultados: J. Diedrich, L. O. Rocha, S. N. Araújo

Produção do texto: J. Diedrich, L. O. Rocha, S. N. Araújo

Revisão e aprovação: L. O. Rocha, S. N. Araújo

FINANCIAMENTO - Não se aplica.

CONSENTIMENTO DE USO DE IMAGEM - Não se aplica.

APROVAÇÃO DE COMITÊ DE ÉTICA EM PESQUISA - Não se aplica.

CONFLITO DE INTERESSES - Não há conflito de interesses.

\section{LICENÇA DE USO}

Os autores cedem à Motrivivência - ISSN 2175-8042 os direitos exclusivos de primeira publicação, com o trabalho simultaneamente licenciado sob a Licença Creative Commons Attribution Non-Comercial ShareAlike (CC BY-NC SA) 4.0 International. Esta licença permite que terceiros remixem, adaptem e criem a partir do trabalho publicado, desde que para fins não comerciais, atribuindo o devido crédito de autoria e publicação inicial neste periódico desde que adotem a mesma licença, compartilhar igual. Os autores têm autorização para assumir contratos adicionais separadamente, para distribuição não exclusiva da versão do trabalho publicada neste periódico (ex.: publicar em repositório institucional, em site pessoal, publicar uma tradução, ou 
como capítulo de livro), com reconhecimento de autoria e publicação inicial neste periódico, desde que para fins não comerciais e compartilhar com a mesma licença.

\section{PUBLISHER}

Universidade Federal de Santa Catarina. Programa de Pós-Graduação em Educação Física. LaboMídia - Laboratório e Observatório da Mídia Esportiva. Publicado no Portal de Periódicos

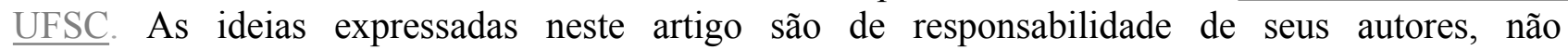
representando, necessariamente, a opinião dos editores ou da universidade.

\section{EDITORES}

Mauricio Roberto da Silva, Giovani de Lorenzi Pires, Rogério Santos Pereira.

\section{EDITOR DE SEÇÃO}

Juliano Silveira

REVISÃO DO MANUSCRITO E METADADOS

João Caetano Prates Rocha; Keli Barreto Santos

\section{HISTÓRICO}

Recebido em: 21 de julho de 2020.

Aprovado em: 11 de setembro de 2020. 